\title{
De ziekte van Peyronie - huidige inzichten
}

\author{
Daan Carel John Mohede ${ }^{1}$ Mels Frank Van Driel ${ }^{1}$ Igle Jan de Jong ${ }^{1} \cdot$ Jack Beck $^{2}$
}

Published online: 14 November 2018

(c) The Author(s) 2018

\section{Samenvatting}

De kennis omtrent de ziekte van Peyronie $(\mathrm{ZvP})$ is in de afgelopen decennia duidelijk toegenomen, maar helaas behoort een curatieve medicamenteuze behandeling nog niet tot de mogelijkheden. Een deel van de patiënten zal voorlopig dus afhankelijk blijven van niet-curatieve, al dan niet chirurgische, symptomatische behandelingen. Uit de meest recente Amerikaanse en Europese richtlijnen en literatuur werd een overzichtsartikel gedestilleerd. We gaan kort in op het ziektebeeld, epidemiologische en historische aspecten en beschrijven vervolgens de bestaande ideeën over de pathofysiologie, pathogenese en de therapeutische mogelijkheden anno 2018.

Trefwoorden ziekte van Peyronie $\cdot$ pathofysiologie $\cdot$ chirurgie $\cdot$ overzichtsartikel

\section{Peyronie's disease-current perspectives}

\begin{abstract}
Although knowledge on Peyronie's disease has increased over the past decades, there is no current curative treatment. Patients will have to depend on symptomatic surgical or medical treatment for the time being. We distilled a research article from the most recent American and European guidelines and literature. We discuss the clinical picture, epidemiological and historical aspects and describe current views on pathophysiology, pathogenesis and therapeutic options.
\end{abstract}

Keywords peyronie's disease $\cdot$ pathophysiology $\cdot$ surgical treatment $\cdot$ research article

\section{Introductie}

De kennis omtrent de Ziekte van Peyronie (kortweg peyronie) is in de afgelopen decennia duidelijk toegenomen. Helaas behoort een curatieve behandeling nog niet tot de mogelijkheden. Patiënten zijn voorlopig afhankelijk van een expectatief beleid of niet-curatieve symptomatische behandelingen.

Uit de meest recente Amerikaanse en Europese richtlijnen en literatuur werd een overzichtsartikel gedestilleerd. We gaan kort in op het ziektebeeld, epidemiologische en historische aspecten en beschrijven vervolgens de bestaande

dr. Jack Beck

j.beck@antoniusziekenhuis.nl

UMC Groningen, Groningen, Nederland

2 St. Antonius Ziekenhuis, Utrecht/Nieuwegein, Nederland ideeën over de pathofysiologie, pathogenese en de therapeutische mogelijkheden anno 2018-2019.

\section{Het ziektebeeld en epidemiologische aspecten}

Peyronie wordt veroorzaakt door veranderingen in de tunica albuginea, het straffe bindweefselkapsel rond de corpora cavernosa van de penis. Peyronie kan onder andere leiden tot pijnlijke erecties, vervorming en kromstand van de penis, verkorting van de penis en erectiele disfunctie (ED) [1]. De zogenaamde plaque, het fibrotische gebied in de tunica albuginea beperkt op de aangedane plaats de expansie van de penis, waardoor een verkromming en/of verkorting en/of insnoering ontstaat. Gedacht wordt dat de peyronie ontstaat door microtraumata in combinatie met een genetische predispositie. Peyronie blijkt meer voor te komen bij NoordEuropese Kaukasiërs, minder bij Afro-Amerikanen en sporadisch bij Aziaten [2]. 
Demografische studies wijzen, in tegenstelling tot hetgeen meestal gedacht wordt, op een hoge prevalentie (tot $9 \%$ ), vooral bij mannen ouder dan 50 [3, 4]. Wereldwijd lijkt de incidentie te stijgen. Dit is waarschijnlijk te verklaren door de beschikbaarheid van orale medicatie voor mannen met ED, die zich zonder erectiepillen niet van de verkromming bewust zouden zijn geworden. Bovendien is er in de afgelopen decennia meer belangstelling voor mannelijke seksuele disfuncties, die zich onder andere uit in toenemende media-aandacht. Tevens wijzen epidemiologische studies op een mogelijke relatie tussen peyronie en cardiovasculaire aandoeningen [5]. Verder zijn een verminderd zelfbeeld, depressieve gedachten en relatieproblemen significant aan peyronie gerelateerd. [6, 7].

\section{Geschiedenis}

Francois Gigot de la Peyronie (1678-1747) staat te boek als degene die de ziekte in 1743 voor het eerst beschreef [8]. Deze Franse chirurg werd geboren in Montpellier, waar hij filosofie en chirurgie studeerde. In 1695 ontving hij zijn diploma als chirurgijn. Hij vervolgde zijn opleiding in Parijs als assistent van Georges Maréschal, chirurg in het Hôpital de la Charité. Na diens dood in 1736, werd De la Peyronie de eerste chirurg van koning Lodewijk XV. Hij reorganiseerde de opleiding tot chirurg en speelde een belangrijke rol in het wetsvoorstel dat leidde tot het verbod voor barbiers om chirurgische ingrepen te verrichten.

De la Peyronie was de eerste die een duidelijke beschrijving van de symptomen van induratio penis plastica (de benaming in het Duitse taalgebied) bood. Peyronie werd echter eeuwen eerder al beschreven als een 'obstakel voor huwelijksgeluk' en onder andere besproken door geleerden als Theodoricus Borgognoni (1205-1298), Wilhelm van Salieto (1210-1276), Andres Vesalius (1514-1564), Gabriele Falloppio (1523-1562), Julius Caesar Arantius (1530-1589) en de Nederlanders Nicolaas Tulp (1593-1674) en Fredrik Ruysch (1638-1731) [9-11].

De la Peyronie dacht dat de ziekte een seksueel overdraagbare aandoening betrof. Hij beschreef de plaques als niet-pijnlijke 'knoppen' die men bij oudere mannen in de wand van de corpora cavernosa kon palperen, enkelvoudig of in rozenkransachtige formaties. Hij merkte ook op dat de curvatuur zich altijd aan dezelfde kant als de plaque bevond. Zijn remedie betrof onder andere het drinken van 'heilig' water uit de bronnen van Barège in de Franse Pyreneeën.

Andere belangrijke namen in de geschiedenis van peyronie zijn George McClellan (eerste chirurgische plaque-excisie in 1828), Oswald Lowsley (plaque-excisie met een vrije vetgraft in 1943), Reed Nesbit (bedacht de ingreep volgens Nesbit voor patiënten met een congenitale peniscurvatuur en publiceerde daarover in 1965), John Pryor (gebruikte de operatie volgens Nesbit voor peyronie in 1979) en Tom Lue (plaque-incisie met veneuze graft in 1997).

\section{Pathofysiologie}

Peyronie leidt tot fibrotische plekken in de tunica albuginea en veroorzaakt hierdoor een verminderde elasticiteit [12]. De normale tunica albuginea bestaat uit weefsel van collageen en elastische vezels die in twee lagen zijn gerangschikt: een in de lengterichting verlopende buitenste laag die zorgt voor verlenging tijdens een erectie en een binnenste circulaire laag die een toename van de omtrek mogelijk maakt. De tunica albuginea wordt gescheiden van het zwelweefsel van de corpora cavernosa door losmazig bindweefsel met daarin een fijn netwerk van bloeden lymfevaten. De veneuze drainage van het spongieuze zwelweefsel vindt plaats via schuin door de tunica albuginea verlopende venules, die uitmonden in de vene dorsalis profunda. De bewegingen van de twee lagen van de tunica albuginea - over elkaar heen - drukken tijdens een erectie deze venules dicht.

\section{Pathogenese}

De meest geaccepteerde theorie is dat het ziekteproces in gang wordt gezet door een mechanisch trauma van de tunica albuginea tijdens erectie, gevolgd door abnormale wondheling en vorming van littekenweefsel. Bij een erectie vult de penis zich met bloed en worden de tunica albuginea en de strengen van het septum tussen de corpora cavernosa uitgerekt tot aan de grens van hun elasticiteit. Dit maakt de omtrek en de lengte van de penis groter. De mate van elasticiteit is enigszins leeftijdgebonden. Als de penis tijdens seksuele gemeenschap weerstand ontmoet, kunnen de septale vezels dusdanig op spanning raken dat ze scheurtjes gaan vertonen. Bij jonge mannen zal dit minder vaak voorkomen dan bij oudere. Bij oudere mannen is de tunica albuginea immers minder elastisch en kan de spanning de binnenste circulaire vezels delamineren [13]. De scheurtjes die zo ontstaan, veroorzaken bloedinkjes en stolselvorming, afzetting van fibrine, fibroblastenproliferatie en een verhoogde vaatmembraanpermeabiliteit. Daarnaast worden er ontstekingscellen gegenereerd. Er ontstaat een infiltraat dat bestaat uit T-lymfocyten, macrofagen en plasmacellen, die de kleine vaten in de subtunicale laag gaan omringen. Het infiltraat leidt tot fibrotische plekken die uiteindelijk de plaque zullen vormen. Dit proces kan 6-18 maanden in beslag nemen. De meeste patiënten ervaren door de inflammatie in de actieve fase een zeurende pijn, 'alsof de penis gekneusd is'. De plaque kan calcificeren en zelfs ossificeren [14-16]. 
Zonder twijfel speelt bij peyronie genetische gevoeligheid een rol, want de ziekte komt onder andere vaak voor in samenhang met andere fibrotische aandoeningen, zoals de ziekte van Dupuytren (kortweg dupuytren) en de ziekte van Ledderhose. In 2011 werd reeds het gelijktijdig bestaan van peyronie en dupuytren onderzocht. In een grote serie werd bij $22 \%$ van de patiënten met peyronie ook dupuytren gevonden [17]. Eerdere studies met kleinere patiëntengroepen meldden een gezamenlijk voorkomen van $0,1-58,8 \%$, een familiair voorkomen van peyronie bij $1-4 \%$ van de patiënten en een familiair voorkomen van dupuytren bij 9,8\% $[18,19]$. Dupuytren wordt evenals peyronie het meest gezien bij het Kaukasische ras. Niet voor niets wordt dupuytren ook wel de Celtic disease genoemd. De prevalentie van peyronie wordt door sommige auteurs zelfs hoger geschat dan die van dupuytren, omdat peyronie zeer waarschijnlijk vanwege het taboe op aandoeningen van de uitwendige geslachtsorganen minder snel zal worden gemeld.

Een studie waarin de genexpressieprofielen van patiënten met peyronie en dupuytren werden vergeleken, toonde vergelijkbare veranderingen in genen die verantwoordelijk zijn voor collageendepositie, afbraak, myofibroblastendifferentiatie en -ossificatie [20].

Hoe peyronie overerft, is niet geheel bekend, maar het lijkt heterogeen. Vaak wordt een autosomale dominantie gezien met variabele penetrantie. Peyronie is zelden recessief autosomaal of maternaal; dat laatste suggereert een mitochondriële erfelijkheid [21, 22].

Dolmans et al. vonden een significante associatie van peyronie met een single nucleotide polymorfisme (SNP) rs 4730775 op het wingless-type mouse mammary tumor virus (MMTV) integration site familie (WNT) 2 locus op chromosoom 7 [23]. WNT2 behoort tot deze WNT-familie, die bestaat uit genen die voor glycoproteïnes coderen. Deze hebben een extracellulaire signalerende functie. Het best beschreven pathway is de canonical pathway, dat de nucleaire (celkern)functie van bètacatenine activeert en zo tot veranderingen leidt in genexpressie, die onder andere proliferatie van myofibroblasten beïnvloeden [24]. Recent onderzoek liet een verhoogd bètacatenine zien, het eindproduct van de WNT-pathway, in cellen uit plaques van patiënten met peyronie [25]. De onderzoekers suggereerden dat de WNT-cascade bij peyronie overgestimuleerd wordt.

Het celbiologisch onderzoek naar verbindingen met antifibrotische eigenschappen staat weliswaar in de kinderschoenen, maar laat veelbelovende resultaten zien. Zo remt verteporfin (een middel dat is geregistreerd voor de behandeling van maculadegeneratie) fibrotische effecten van myofibroblasten [26].

\section{Klinische en diagnostische aspecten}

Peyronie kan tijdens het hele volwassen leven ontstaan, met een mediane leeftijd van 53 jaar. De prevalentie wordt geschat op 3-9\% van alle volwassen mannen [27]. Peyronie presenteert zich in twee fasen: een inflammatoire fase, die 6-18 maanden duurt, met pijnlijke erecties en de ontwikkeling van plaques en vervorming van de penis, gevolgd door een chronische fase, die wordt gekenmerkt door 'stabiele' plaques, die echter nog wel kunnen calcificeren of ossificeren. Tevens zal de penis na verloop van tijd korter worden en kan er ED optreden in de zin van verminderde rigiditeit [28]. Men spreekt na drie maanden zonder veranderingen in de kromstand van een status quo, van 'stabiele' ziekte.

Vaak zijn patiënten bang voor verlies van hun seksueel functioneren en maken zij zich zorgen over het toekomstig beloop. Soms is er zelfs sprake van angst voor kanker. De vervorming kan zo ernstig zijn dat intromissie vaginalis onmogelijk dan wel zeer pijnlijk wordt. Het ervaren van moeilijkheden tijdens gemeenschap is uiteraard niet alleen afhankelijk van de ernst van de kromstand, maar ook van de partnerrelatie. Een alleenstaande, maar wel seksueel actieve man met een ernstige vormafwijking lijdt over het algemeen meer onder de verschijnselen dan een man met een vaste, stabiele relatie. Er zijn geen onderzoeken bekend of er wat betreft het bovenstaande verschillen zijn tussen hetero- en homoseksuele mannen.

Peyronie kan veel stress veroorzaken, zowel bij de patiënt als zijn partner. In dat verband is het zeer belangrijk de partner te betrekken bij de uitleg over peyronie. Het is belangrijk de situatie bij anvang objectief in beeld te krijgen, bij voorkeur middels foto's in drie richtingen. Soms is dat ook in het vervolgtraject van belang, in het bijzonder als het gaat om adviezen ten aanzien van wel of niet opereren. Een foto van de stijve penis van boven geeft een idee over mogelijk laterale verkromming, een van lateraal genomen over dorsale of ventrale verkromming en een vanuit frontaal gemaakte foto biedt vooral informatie over een mogelijke rotatie. Een PDE5-remmer of een intracaverneuze injectie met een vasodilaterend medicijn (bijvoorbeeld papaverine/fentolamine) kan gebruikt worden als er ook ED is. De precieze hoek van de curvatuur kan eventueel worden vastgesteld met behulp van een goniometer.

Het lichamelijk onderzoek moet nauwkeurig gebeuren. De glans moet vastgepakt worden tussen de vinger en duim van de niet-dominante hand om vervolgens de penis voorzichtig te strekken en zo de resterende elasticiteit te bepalen. Verlies van elasticiteit duidt op fibrose. De gestrekte penis wordt met een liniaal gemeten, van de glans tot aan de overgang van penis naar abdomen. Het is belangrijk de lengte goed vast te leggen, juist omdat bij vrijwel alle patiënten al 
vóór een chirurgische interventie verkorting is opgetreden. De uiteinden van de plaque worden gepalpeerd tussen duim en wijsvinger van de dominante hand, beide lateraal van de schacht. Het gaat soms namelijk om discrete veranderingen. Dorsale plaques komen verreweg het meest voor en kunnen makkelijk worden onderscheiden van ventrale plaques. Bij minder dan 5\% van alle patiënten met peyronie is er sprake van plaquevorming aan de ventrale zijde van de penis [1]. Lateraal gelokaliseerde plaques kunnen significante coïtusproblemen veroorzaken. Vooral het doorstoten bij coïtus kan tot pijnklachten bij de vrouw leiden, maar vanzelfsprekend ook al bij intromissie. Plaques die bijna de gehele schacht omgeven, kunnen resulteren in het zogenaamde zandloperfenomeen. De locatie van de plaque moet uiteraard worden genoteerd, maar dit vereist ervaring. Een schatting van de plaquegrootte met de hand door een onervaren onderzoeker is niet betrouwbaar. Tevens moet naar aanwijzingen voor het bestaan van dupuytren en de ziekte van Ledderhose gezocht worden. De Peyronie's Disease Questionnaire (PDQ) kan als leidraad gebruikt worden bij anamnese en lichamelijk onderzoek en is vooral van belang als het onderzoek deel uitmaakt van wetenschappelijk onderzoek [29]. De Nederlandse variant, de NL-PDQ, wordt momenteel gevalideerd.

Uitgebreide onderzoeken zijn in de beginnende fase van de ziekte niet altijd nodig. Onder experts is het diagnostische nut van duplexechografie echter geaccepteerd. Typische bevindingen zijn verdikking van de tunica albuginea, calcificaties en septale fibrose. Bij patiënten met een bijkomende ED kunnen arteriële en veno-occlusieve disfunctie beoordeeld worden. Om deze reden is het belangrijk de echoduplex te combineren met een erectietest. De erectie wordt dan opgewekt met fentolamine/papaverine of alprostadil.

Met magnetic resonance imaging (MRI) kunnen gedetailleerde afbeeldingen van plaques gemaakt worden, maar een dergelijk onderzoek is tijdrovend en duur en derhalve anno 2018/2019 alleen geïndiceerd bij 'moeilijke' casus, bijvoorbeeld bij patiënten met een zandloperfenomeen.

Bij naar schatting 3-13\% van de patiënten treedt geheel of gedeeltelijke spontane remissie op [30]. Hierover moeten patiënt en partner bij het bespreken van de behandelopties geïnformeerd worden. Aangezien peyronie vaker lijkt voor te komen bij diabetes en geassocieerd wordt met androgeendeficiëntie is het verstandig om bij de poliklinische evaluatie het serumglucose, versuikerd hemoglobine ( $\mathrm{HbA} 1 \mathrm{C})$, totaaltestosteron, vrij testosteron en luteïniserend hormoon te bepalen [27].

\section{Therapie}

Er is geen consensus over de optimale behandelstrategie $[1,9,19,31]$. Hoewel bij vrijwel alle patiënten pijnklachten na verloop van enkele weken tot maanden spontaan verdwijnen, geldt dat niet voor de vervorming van de penis (verkromming, ontstaan van zandloperpenis, verkorting etc.).

\section{Niet-chirurgische therapie}

Op collagenase clostridium histolyticum na zijn alle farmacotherapeutische opties off label in het gebruik. Beschreven zijn het gebruik van onder andere orale medicatie (pentoxifylline en kaliumpara-aminobenzoaat (PABA)), intralaesionale injecties (verapamil, interferon, vitamine $\mathrm{E}$ en corticoïden), alsmede transcutane iontoforese met verapamil en dexamethason. Dergelijke behandelingen zijn bij sommige patiënten succesvol, maar in de Europese richtlijnen krijgt geen van genoemde mogelijkheden tot op heden een graad A-aanbeveling [19].

Collagenase clostridium histolyticum is het eerste medicijn dat door de Amerikaanse Food and Drug Administration (FDA) en de Europese autoriteiten officieel is geregistreerd voor de behandeling van peyronie, zij het met bepaalde restricties.

Behandeling met orale steroïden, vitamine $\mathrm{E}$ en tamoxifen moet vermeden worden. Laagintensieve schokgolfbehandeling kan eventueel gebruikt worden ter vermindering van de pijn en tractieapparatuur om vormafwijkingen en verlies van peniele lengte tegen te gaan. De tractie kan echter zeer pijnlijk zijn en de effectiviteit hangt sterk af van de therapietrouw. Radiatie werd empirisch gebruikt met sterk wisselende resultaten [32]. Lagedosis-radiotherapie (RT) in de beginfase van de ziekte is mogelijk effectief bij patiënten met pijnlijke erecties die na verloop van tijd aanhouden c.q. niet verminderen. Volgens de European Society for Sexual Medicine (ESSM) is er echter geen bewijs voor de werkzaamheid, maar draagt bestraling wel bij aan het risico op lokale complicaties en moet deze behandeling om die reden als obsoleet worden beschouwd [27].

De resultaten van niet-chirurgische therapie zijn moeilijk te interpreteren, gezien de variaties in studieopzet, patiëntenpopulatie, behandelduur en/of gebruikte dosering [27]. Een grote beperking van vergelijkende studies is het gebruik van verschillende eindpunten. Vermindering van vormafwijking van de stijve penis (curvatuur, vernauwing, verkorting) zijn de meest gebruikte uitkomstmaten. Een drieledige studieopzet (behandeling $v s$. placebo $v s$. geen behandeling) met een duur van minstens 18 maanden geniet vanzelfsprekend de voorkeur [33]. Dergelijk onderzoek blijkt in de praktijk echter onmogelijk. 


\section{Collagenase clostridium histolyticum (CCH)}

In de fibrotische plaque worden drie types collageen aangetroffen. $\mathrm{CCH}$ is een mix van twee enzymen die zijn gericht op collageen type I en III, welke worden gevonden in botten, bindweefsel, littekenweefsel en plaques. Het werkingsmechanisme van $\mathrm{CCH}$ bestaat uit het binden aan en detorderen of strekken van de tripelcollageen helix en het denatureren van de eiwitverbindingen [34].

$\mathrm{CCH}$ spaart in theorie collageen type IV, dat voornamelijk wordt aangetroffen in bloedvaten en zenuwbanen. In-vitro- en in-vivostudies laten zien dat $\mathrm{CCH}$ toch effect heeft op collageen type IV en dat er schade kan optreden aan kleinere venen en zenuwbanen, wat een verklaring kan zijn voor een forse toename in incidentie van pijn en hematoomvorming na $\mathrm{CCH}$-injecties in vergelijking met de pijnklachten en hematoomvorming na een injectie met fentolamine/papaverine of alprostadil.

In 2013 werden de resultaten van de IMPRESS (Investigation for Maximal Peyronie's Reduction Efficacy and Safety Studies) I en II gepubliceerd. Er werden in deze twee identieke, prospectieve, multicentrische, gerandomiseerde, dubbelblinde, placebogecontroleerde fase-III-studies in totaal 832 patiënten geïncludeerd. De proefpersonen kregen vier series van twee injecties, waarbij er zes weken tussen iedere serie zat en 24-72 uur tussen beide injecties per serie. De patiënten kregen de opdracht om driemaal daags de plaque bij slappe penis te buigen en de penis te strekken. Ook werd geadviseerd om bij erectie de penis subtiel recht te buigen. De CCH-groep toonde gemiddeld $34 \%$ verbetering ten opzichte van $18 \%$ in de placebogroep [35].

Een interessant gegeven was dat ondanks de beperkte vermindering in kromstand, $70 \%$ van de seksuele vrouwelijke partners meldde na de behandeling een beter seksleven te hebben [36]. Bovendien rapporteerde $57 \%$ van hen dat de relatie 'overall' was verbeterd. Een mogelijke, maar enigszins gezochte verklaring zou kunnen zijn dat er optisch weliswaar niet veel verbetering te zien was, maar dat door de $\mathrm{CCH}$ de plaque zachter was geworden, waardoor de stijve penis bij geslachtsverkeer beter meebuigt.

Praktische nadelen van het oorspronkelijke Amerikaanse behandelschema zijn het aantal injecties (8), de kosten (ruim 800 euro per injectie) en het lastig te plannen injectieschema op de polikliniek. In Engeland loopt momenteel een trial met drie keer een maandelijkse injectie met $\mathrm{CCH}$ in combinatie met het twee keer per dag gebruiken van een vacuümpomp gedurende drie maanden. De voorlopige resultaten laten zien dat de uitkomsten even goed zijn als die van het oorspronkelijke schema, maar wel veel goedkoper en beter te plannen [37]. Nadelen zijn dat de patiënt zelf een vacuümpomp dient aan te schaffen en dat het resultaat erg afhankelijk is van de compliantie.

\section{Chirurgische therapie}

Het doel van chirurgie is het corrigeren van de curvatuur om coïtusproblemen te verminderen. Chirurgie is pas geïndiceerd als er sprake is van stabiele ziekte en serieuze moeilijkheden bij gemeenschap. Specifieke complicaties die besproken moeten worden tijdens de counseling zijn het risico op ED, een verminderd gevoel in de glans door neuropraxie van de dorsale zenuwbundel, recidiefkans van de kromstand, palpabele of pijnlijke knopen van onoplosbare hechtingen onder de huid, en verdere verkorting van de penis. Het wordt, zoals eerder vermeld, om die reden aanbevolen de gestrekte penislengte preoperatief te bepalen, zodat patiënten zich realiseren dat het totale lengteverlies niet alleen te wijten is aan de operatie, maar ook aan de peyronie zelf [38]. Het is verstandig pre- per- en post-
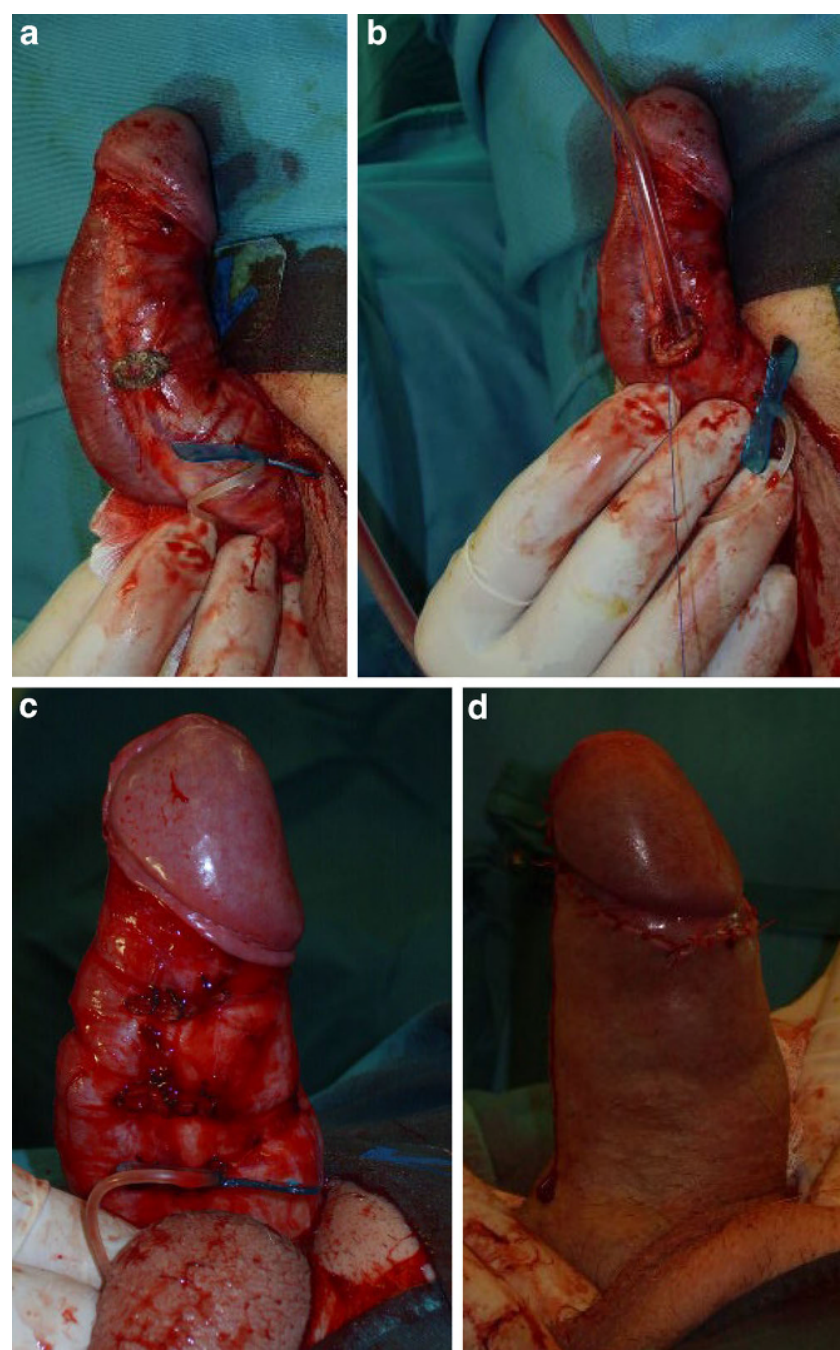

Figuur 1 Ingreep volgens Nesbit. a afgestroopte penis na circumcisie, kunstmatig in erectie gebracht met $\mathbf{b}$ gemarkeerde ellips op de tunica albuginea. De eerder gemarkeerde ellips na excisie (c), waarna het ontstane defect is gesloten met hechtingen. d de uiteindelijk rechte besneden penis in erectie 


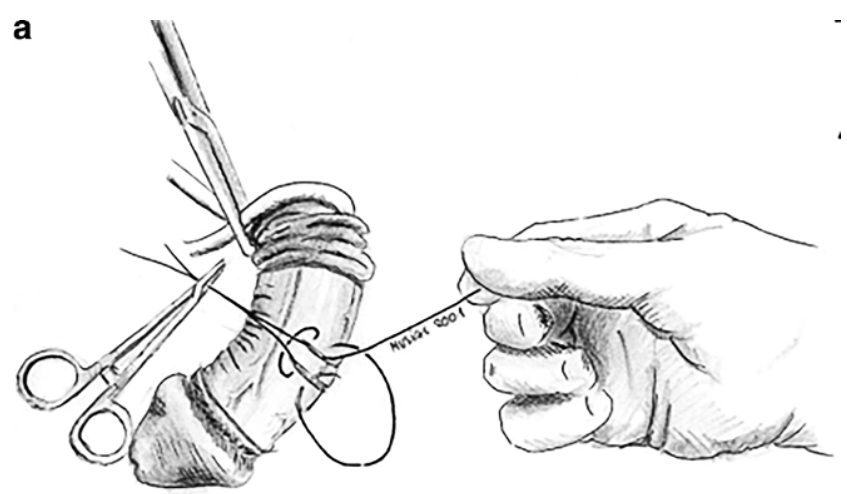

b

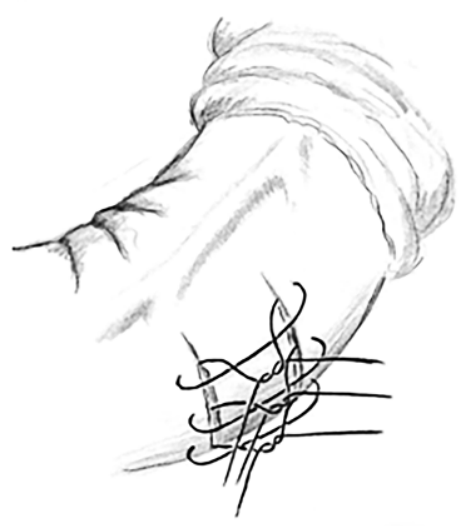

Figuur 2 Cavernoplicatie volgens Essed-Schröder. Bron: Gholami et al. [41] met toestemming overgenomen

operatief foto's te verkrijgen en deze in het dossier vast te leggen, uiteraard na toestemming van de patiënt.

\section{Nesbit-procedure en andere verkortende technieken}

In 1965 beschreef Reed Nesbit als eerste het excideren van ellipsen uit de tunica albuginea, om zo patiënten met een congenitale peniscurvatuur te behandelen [39]. Veertien jaar later werd dezelfde techniek voor het eerst gebruikt voor Peyronie (zie fig. 1; [40]). Als de penis preoperatief

Figuur 3 12-stip-cavernoplicatie volgens Gholami. Bron: Gholami et al. [41] met toestemming overgenomen

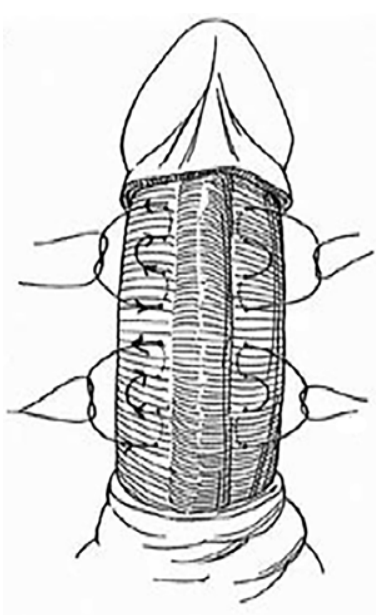

niet te kort is, kiezen de meeste urologen voor de Nesbitprocedure of een andere verkortende techniek, zoals die van Essed-Schroder (zie fig. 2), Yachia, Luc of de 16-stippen cavernoplicatie volgens Gholami (zie fig. 3; [41]).

Voordelen van dergelijke ingrepen zijn de korte operatieduur, de eenvoud ervan, het ontbreken van negatieve effecten op de hemodynamiek van de erectie, en het belangrijkst, het effectief rechter maken van de penis. Nadelen zijn de verdere verkorting en het feit dat zandloper- en andere complexe afwijkingen (rotatie) niet goed gecorrigeerd kunnen worden. Daarnaast kunnen hechtingen die de penis in het gelid houden, doorscheuren en zo tot een recidief kromstand leiden. Als vuistregel geldt dat een Nesbit-procedure en varianten daarop alleen worden aanbevolen bij patiënten met een penislengte in erectie van ten minste $12 \mathrm{~cm}$, gemeten aan de convexe zijde. Onze ervaring leert dat bij kleinere penissen er een dermate postoperatieve verkorting ontstaat, dat coïtus ondanks de rechte penis nog steeds niet goed mogelijk is.

\section{Plaque-incisie of -excisie met grafting (IEG)}

Bij patiënten met een zeer forse kromstand, uitgebreide calcificaties, een zandloperfenomeen of een penislengte van $<12 \mathrm{~cm}$ bij maximaal strekken, is het verstandig een nietverkortende procedure als plaque-IEG te bespreken (zie fig. 2). Dit soort ingrepen leidt niet tot een langere penis (!). Het grootste nadeel van IEG is dat er regelmatig (20-30\%) sensibiliteitsverlies van de glans optreedt als gevolg van het mobiliseren van de vaatzenuwbundel. Meestal is dit echter tijdelijk (zie fig. 4).

Iatrogene ED kan het gevolg zijn van een inflammatoire reactie en fibrose onder de graft met schade aan het gladde spierweefsel van de corpora en/of veneuze lekkage als gevolg. Deze technieken kunnen op zich wel worden toegepast bij patiënten met een preoperatief al verminderde rigiditeit, maar dan dienen zij voorbereid te worden op het postoperatief moeten toepassen van bijvoorbeeld intraca-
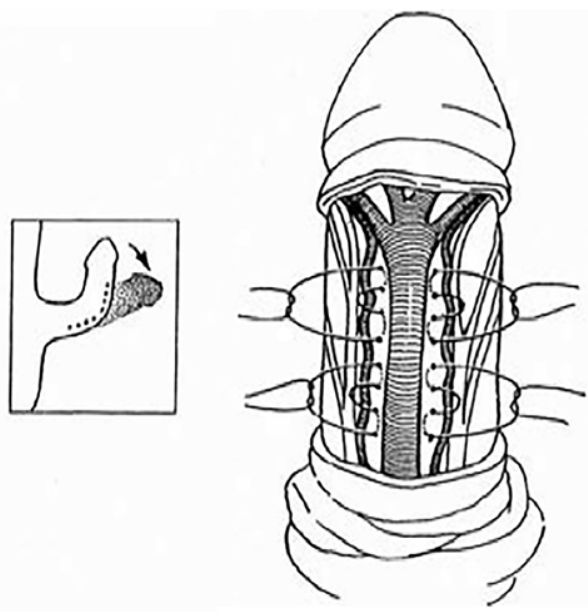

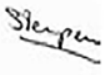


Figuur 4 Plaque-IEG (bovien pericard). a afgestroopte penis na circumcisie, kunstmatig in erectie gebracht. b defect in de tunica albuginea na plaque incisie. De neurovasculaire bundel is met een geel elastiekje geïsoleerd. c het defect bedekt met bovien pericardgraft (de neurovasculaire bundel is nog niet teruggelegd). d penis in erectie
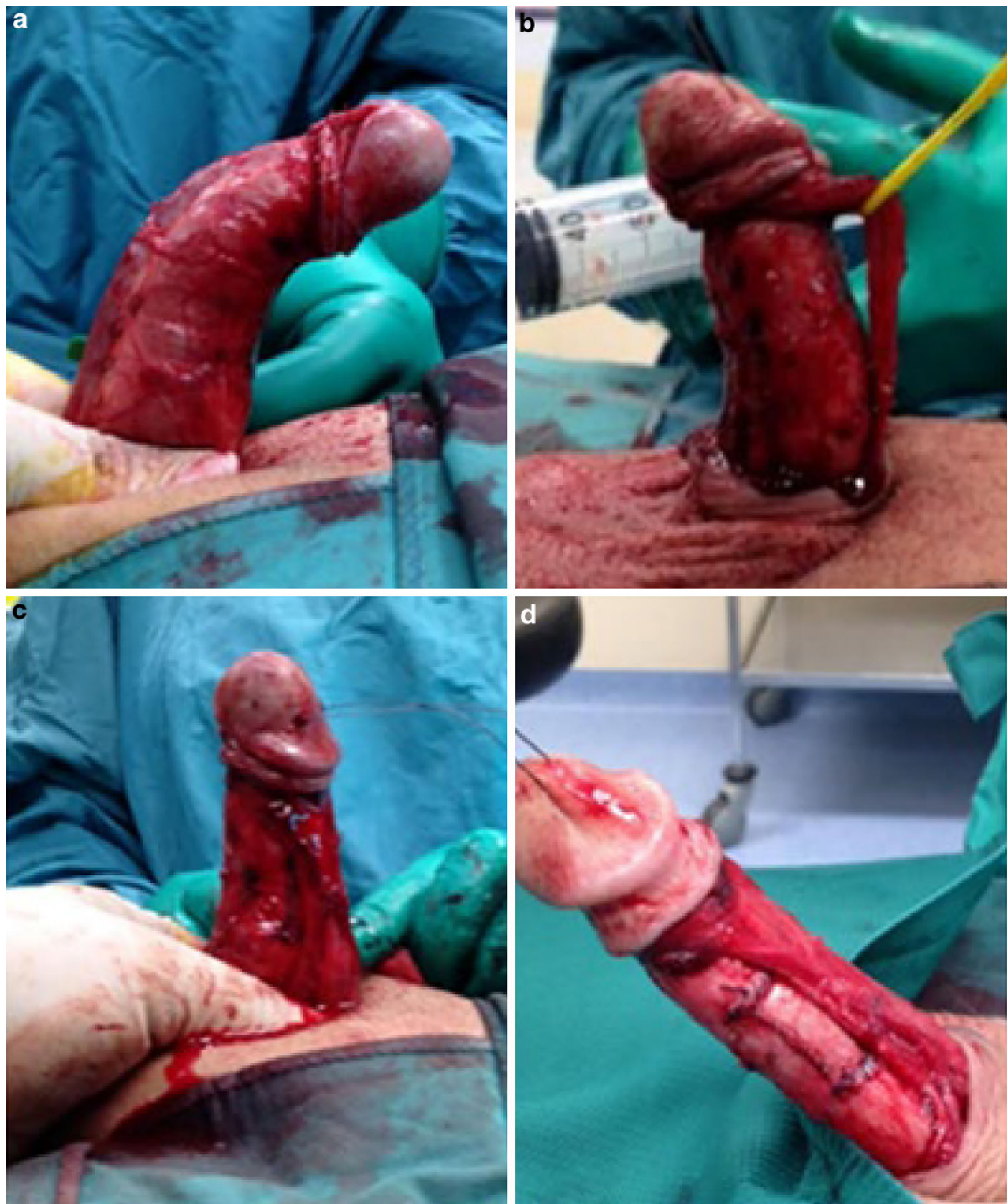

verneuze zelfinjectie met fentolamine papaverine, in het slechtste geval, het implanteren van een erectieprothese.

De meest gebruikte autologe materialen om het defect in de TA te bedekken, zijn de vena saphena, de huid, het wang- of lipslijmvlies, de fascie van de musculus rectus abdominis en de fascia lata. De meest toegepaste extracellulaire matrix-graftmaterialen zijn het pericard van humane en boviene kadavers, dunne-darmmucosa van varkens en de fascia lata van kadavers. Tevens kunnen synthetische grafts gebruikt worden, die humaan fibrinogeen en trombine bevatten of polytetrafluoro-ethyleen [42].

De zoektocht naar de ideale graft is nog lang niet voltooid. Belangrijke criteria met betrekking tot de keuze voor een bepaalde graft zijn of ze gemakkelijk te verkrijgen zijn, of ze weinig gevoelig zijn voor infectie, hun flexibiliteit, in welke mate ze de erectiele functie behouden, de kostenef- fectiviteit ervan en of ze gemakkelijk zijn aan te passen aan de defectgrootte.

De indicatiestellingen voor behandeling middels IEG en $\mathrm{CCH}$ komen nog niet overeen. $78 \%$ van de patiënten die voor IEG kiezen, heeft achteraf spijt [nog niet gepubliceerde data urologie UMCG]. Om deze reden is het anno 2018-2019 verstandig om als behandelalternatief te bespreken om de laesie te injecteren met collagenase $(3 \times$ een maandelijkse injectie met $\mathrm{CCH}$ in combinatie met drie maanden $2 \times$ per dag vacuümpompoefeningen) en om aan te zien of een IEG kan worden voorkomen of uitgesteld.

\section{Implantatie van een prothese}

Mannen die lijden aan zowel peyronie als ED reageren niet altijd goed op PDE5-remmers of intracaverneuze in- 
jecties. In zulke gevallen heeft een operatieve correctie van de kromstand uiteraard geen zin. Bij deze patiënten dient het implanteren van een hydraulische oppompbare of semirigide erectieprothese overwogen te worden. Met de cilinders in situ en maximaal opgepompt, wordt de plaque gekraakt, zodat de kromstand vermindert. Gecalcificeerde plaques kunnen ook worden geëxcideerd, waarna het defect kan worden bedekt met een graft. Over het algemeen garandeert een dergelijke ingreep voldoende rigiditeit voor seksuele gemeenschap.

Ondanks adequate voorlichting zal ongeveer $50 \%$ van de patiënten echter ontevreden blijken over de penislengte. Bij deze groep kan een gelijktijdige penisverlengende operatie overwogen worden door specifieke incisies in de tunica albuginea en/of klieven van het ligamentum suspensorium, het ophangbandje van de penis en/of het verrichten van een penoscrotale huidplastiek [43].

\section{Verwachtingen en psychologische aspecten}

Peyronie is onomstotelijk een goed gedefinieerde klinische entiteit. De ziekte kan de zelfverzekerdheid van mannen ten aanzien van seksualiteit aantasten en counseling - bij voorkeur in tempi - is om die reden zeer belangrijk [44]. Veel mannen hebben namelijk onrealistische verwachtingen ten aanzien van het resultaat van de behandelingen. Patiënten moet duidelijk gemaakt worden dat de chirurgische doelstelling is om de penis functioneel 'recht' (gedefinieerd als minder dan $10-20^{\circ}$ afwijkend) te krijgen en dat verdere verkorting inherent is aan de operatie volgens Nesbit en variaties daarop.

Meerdere onderzoeken hebben duidelijk gemaakt dat peyronie tot psychische problemen kan leiden. Depressie en relatieproblemen staan daarbij op de voorgrond [45]. Het wordt dan ook aanbevolen om bij het eerste bezoek te vragen naar klachten die wijzen op stress en depressie, al dan niet met behulp van gevalideerde vragenlijsten. Daarnaast dient er meer onderzoek te worden gedaan naar het beloop van psychische klachten en de mogelijke weerslag van peyronie op de partner en de relatie. In dat verband verdienen homoseksuele patiënten met peyronie speciale aandacht, omdat de huidige richtlijnen alleen betrekking hebben op heteroseksuele mannen.

\section{Tot slot}

Peyronie is een goed gedefinieerde entiteit. Kennis op genetisch en celbiologisch gebied zal in de nabije toekomst meer informatie en hopelijk ook nieuwe behandelmogelijkheden gaan bieden. Goede counseling, voorlichting en psychische ondersteuning zijn voor patiënten met peyronie van cruciaal belang.

Open Access This article is distributed under the terms of the Creative Commons Attribution 4.0 International License (http:// creativecommons.org/licenses/by/4.0/), which permits unrestricted use, distribution, and reproduction in any medium, provided you give appropriate credit to the original author(s) and the source, provide a link to the Creative Commons license, and indicate if changes were made.

\section{Literatuur}

1. Ralph D, Gonzalez-Cadavid N, Mirone V, Perovic S, Sohn M, Usta $\mathrm{M}$, et al. The management of Peyronie's disease: evidence-based 2010 guidelines. J Sex Med. 2010;7(7):2359-74.

2. Sommer F, Schwarzer U, Wassmer G, Bloch W, Braun M, Klotz $\mathrm{T}$, et al. Epidemiology of Peyronie's disease. Int J Impot Res. 2002;14:379-83.

3. Mulhall JP, Creech SD, Boorjian SA, Ghaly S, Kim ED, Moty A, et al. Subjective and objective analysis of the prevalence of Peyronie's disease in a population of men presenting for prostate cancer screening. J Urol. 2004;171(6):2350-3. Part 1.

4. Kumar B, Narang T, Gupta S, Gulati M. A clinico-aetiological and ultrasonographic study of Peyronie's disease. Sex Health. 2006;3(2):113-8.

5. Rosen R, Catania J, Lue T, Althof S, Henne J, Hellstrom W, et al. Impact of Peyronie's disease on sexual and psychosocial functioning: qualitative findings in patients and controls. J Sex Med. 2008;5(8):1977-84.

6. Smith JF, Walsh TJ, Conti SL, Turek P, Lue T. Risk factors for emotional and relationship problems in peyronie's disease. J Sex Med. 2008;5(9):2179-84.

7. Bjekic MD, Vlajinac HD, Sipetic SB, Marinkovic JM. Risk factors for Peyronie's disease: a case-control study. BJU Int. 2006;97(3):570-4.

8. de la FGP. Sur quelques obstacles qui s'opposent à l'éjaculation naturelle de la semence. Mém Acad Roy Chir. 1743;1:318-33.

9. Hauck EW, Diemer T, Schmelz HU, Weidner W. A critical analysis of nonsurgical treatment of Peyronie's disease. Eur Urol. 2006;49(6):987-97.

10. Musitelli SMD, Maurizio Bossi MD, Jallous HM. A brief historical survey of "Peyronie's disease.". J Sex Med. 2008;5:1737-46.

11. Haneveld GT. Early Dutch contributions on Peyronie's disease. Arch Chir Neerl. 1979;31(3):123-9.

12. Gelbard MK, James K, Riach P, Dorey F. Collagenase versus placebo in the treatment of Peyronie's disease: a double-blind study. J Urol. 1993;149(1):56-8.

13. Devine CJ, Somers KD, Jordan SG, Schlossberg SM. Proposal: trauma as the cause of the Peyronie's lesion. J Urol. 1997;157(1): 285-90.

14. Vermooten V. Metaplasia in the penis. The presence of bone, bone marrow and cartilage in the glans. N Engl J Med. 1933;209:368-70.

15. Bett WR. The os penis in man and beast. Ann R Coll Surg Engl. 1952;10:405-9.

16. Sarma DP, Weilbaecher TG. Human os penis. Urology. 1990;35: $349-50$.

17. Nugteren HM, Nijman JM, Jong IJ de, Driel MF van. The association between Peyronie's and Dupuytren's disease. Int J Impot Res. 2011;23(4):142-5.

18. Dolmans GH, Bock GH de, Werker PM. Dupuytren diathesis and genetic risk. J Hand Surg Am. 2012;37:2106-11. 
19. Hatzimouratidis K, Eardley I, Giuliano F, Hatzichristou D, Moncada I, Salonia A, et al. EAU guidelines on penile curvature. Eur Urol. 2012;62:543-52.

20. Qian A, Meals RA, Rajfer J, Gonzalez-Cadavid NF. Comparison of gene expression profiles between Peyronie's disease and Dupuytren's contracture. Urology. 2004;64(2):399-404.

21. Wilma B, Nyberg LM Jr., Hochberg MC, Walsh PC, Opitz JM. Peyronie's disease: a newly recognized autosomal-dominant trait. Am J Med Genet. 1982;12(2):227-35.

22. Michou L, Lermusiaux JL, Teyssedou JP, Bardin T, Beaudreuil J, Petit-Teixeira E. Genetics of Dupuytren's disease. Joint Bone Spine. 2012;79(1):7-12.

23. Dolmans GH, Werker PM, Hennies HC, Furniss D, Festen EA, Franke L, et al. Wnt signaling and Dupuytren's disease. N Engl J Med. 2011;365(4):307-17.

24. Moon RT, Kohn AD, De Ferrari GV, Kaykas A. WNT and beta-catenin signalling: diseases and therapies. Nat Rev Genet. 2004;5(9):691-701.

25. De Young LX, Bella AJ, O'Gorman DB, Gan BS, Lim KB, Brock GB. Protein Biomarker analysis of primary Peyronie's disease cells. J Sex Med. 2010;7(1):99-106.

26. Mohede DCJ, Bank RA, Driel MF van, Jong IJ de. Anti-fibrotic effects of verteporfin on myofibroblasts in Peyronies disease. Sex Med 2018;S2050-1161(18) [Epub ahead of print]

27. Garaffa G, Trost LW, Serefoglu EC, Ralph D, Hellstrom WJG. Understanding the course of Peyronie's disease. Int J Clin Pract. 2013;67:781-8.

28. Mulhall JP, Schiff J, Guhring P. An analysis of the natural history of Peyronie's disease. J Urol. 2006;175(June):2115-8. discussion 2118.

29. Coyne KS, Currie BM, Thompson CL, Smith TM. Responsiveness of the Peyronie's Disease Questionnaire ( PDQ ). J Sex Med. 2015;12(4):1072-9.

30. Bekos A, Arvaniti M, Hatzimouratidis K, Moysidis K, Tzortzis V, Hatzichristou D. The natural history of Peyronie's disease: an ultrasonography-based study. Eur Urol. 2008;53(3):644-51.

31. Nehra A, Alterowitz R, Culkin DJ, Faraday MM, Hakim LS, Heidelbaugh JJ, et al. Peyronie's disease: AUA guideline. J Urol. 2015;194(3):745-53.

32. Mulhall JP, Hall M, Broderick GA, Incrocci L. Radiation therapy in Peyronie's disease. J Sex Med. 2012;9(5):1435-41.

33. Pryor JP, Ralph DJ. Clinical presentations of Peyronie's disease. Int J Impot Res. 2002;14(5):414-7.

34. Cwikla DJ, Yafi FA. Intralesional collagenase Clostridium histolyticum in the management of Peyronie's disease: current best practice. Ther Adv Urol. 2018;10(4):139-53.
35. Gelbard M, Goldstein I, Hellstrom WJ, McMahon CG, Smith T, Tursi J, Jones N, Kaufman GJ, Carson CC. Clinical efficacy, safety and tolerability of collagenase clostridium histolyticum for the treatment of peyronie disease in 2 large double-blind, randomized, placebo controlled phase 3 studies. J Urol. 2013;190(1): 199-207.

36. Goldstein I, Knoll LD, Lipshultz LI, Smith T, Kaufman GJ, McMahon CG. Changes in the effects of Peyronie's disease after treatment with Collagenase Clostridium histolyticum: Male patients and their female partners. Sex Med. 2017;5(2):e124-e30.

37. Raheem AA, Johnson M, Abdel-Raheem T, Capece M, Ralph D. Collagenase Clostridium histolyticum in the treatment of Peyronie's disease-A review of the literature and a new modified protocol. Sex Med Rev. 2017;5(4):529-35.

38. Smith JF, Walsh TJ, Lue TF. Peyronie's disease: a critical appraisal of current diagnosis and treatment. Int $\mathrm{J}$ Impot Res. 2008;20(5):445-59.

39. Nesbit R. Congenital curvature of the phallus: report of three cases with description of corrective operation. J Urol. 1965;93:230-2.

40. Pryor JPFJ. A new approach to the correction of penile deformity in Peyronie's disease. J Urol. 1979;122:622-3.

41. Gholami SS, Lue TF. Correction of penile curvature using the 16-dot plication technique: a review of 132 patients. J Urol. 2002;167(5):2066-9.

42. Kadioglu A, Sanli O, Akman T, Ersay A, Guven S, Mammadov F. Graft materials in peyronie's disease surgery: a comprehensive review. J Sex Med. 2007;4:581-95.

43. Anaissie J, Yafi FA. A review of surgical strategies for penile prosthesis implantation in patients with Peyronie's disease. Transl Androl Urol. 2016;5(3):342-50.

44. Perneger TV. What is wrong with Bonferroni adjustments. $\mathrm{Br}$ Med J. 1998;316(7139):1236-8.

45. Terrier JE, Nelson CJ. Psychological aspects of Peyronie's disease. Transl Androl Urol. 2016;5(3):290-5.

drs. Daan Carel John Mohede arts-assistent urologie

dr. Mels Frank Van Driel uroloog

prof. dr. Igle Jan de Jong uroloog

dr. Jack Beck uroloog 